
Brasileira 26: 537-539.

\title{
Produtividade e morfologia de acessos de caupi, em Mossoró, RN
}

\author{
Salvador B Torres ${ }^{1}$; Fabrícia N de Oliveira ${ }^{2}$; Regina C de Oliveira ${ }^{3}$; João B Fernandes ${ }^{4}$ \\ 'EMPARN/UFERSA-Depto Ciências Vegetais, C. Postal 137, 59625-900 Mossoró-RN; ${ }^{1}$ UFERSA-Depto Ciências Vegetais; ${ }^{4}$ EMPARN/ \\ Embrapa, C. Postal 188, 59062-900 Natal-RN; 2Estudante; bolsista CNPq; sbtorres@ufersa.edu.br
}

\section{RESUMO}

O objetivo deste trabalho foi avaliar a produtividade e caracterizar a morfologia de dez acessos de caupi [Vigna unguiculata (L.) Walp.], nas condições edafoclimáticas do município de Mossoró, RN. Dez acessos (Amapá, BRS Potiguar, Canapu, Casca-de-seda, Coruja, Costela-de-vaca, João-vieira, Pingo-de-ouro, Rabo-de-peba e Sempre-verde) foram avaliados em experimento de campo, de agosto/2006 a junho/2007, em Mossoró. Verificou-se que todos os genótipos de caupi apresentaram hábito de crescimento indeterminado e semi-enramador volúvel, exceto o 'BRS Potiguar' que revelou comportamento semi-enramador. $\mathrm{O}$ número de sementes variou de 12 a 16 por vagem. Para a região de Mossoró, pode ser indicado como melhor alternativa ao produtor, o acesso Amapá, por ser mais precoce, possuir maior número de vagens por planta e maior produtividade, seguido de BRS Potiguar e Casca-de-seda.

Palavras-chave: Vigna unguiculata, morfologia vegetal, rendimento.

\begin{abstract}
Yield and morphology of cowpea accessions in Mossoró, Rio Grande do Norte State, Brazil

The objective of this work was to evaluate the productivity and to describe the morphology of ten cowpea [Vigna unguiculata (L.) Walp.] accessions in the edaphoclimatic conditions of Mossoró, Brazil. The accessions Amapá, BRS Potiguar, Canapu, Casca-de-seda, Coruja, Costela-de-vaca, João-vieira, Pingo-de-ouro, Rabo-de-peba and Sempre-verde were evaluated in a field experiment from August 2006 to June 2007. The majority of accessions was of indeterminate and semi-branched voluble growth habit; only BRS Potiguar was semibranched. The number of seeds per pod varied from 12 to 16 . For the Mossoró region, the accession Amapá is considered be the best alternative for small farmers. This accession is earlier maturing, presents a high number of pods per plant and high yield. Other promising genotypes are BRS Potiguar and Casca-de-seda.
\end{abstract}

Keywords: Vigna unguiculata, plant morphology, yield.

(Recebido para publicação em 17 de outubro de 2007; aceito em 1 de outubro de 2008) (Received in October 17, 2007; accepted in October 1, 2008)

$\mathrm{O}$ caupi [Vigna unguiculata (L.) Walp.], conhecido no Nordeste brasileiro por feijão-macassar ou feijão-decorda, é uma cultura de grande importância para o desenvolvimento agrícola da região Nordeste, tanto no aspecto econômico quanto no nutricional, pois é o alimento básico na dieta das populações mais carentes, exercendo função social no suprimento das necessidades nutricionais dessa camada da população.

No Brasil, o caupi é cultivado predominantemente no sertão semi-árido da região Nordeste e em pequenas áreas na Amazônia (Maia, 1986). Ainda segundo este autor, é uma das leguminosas mais adaptadas, versáteis e nutritivas (23-25\% de proteína) entre as espécies cultivadas. A cultura ocupa cerca de 11 milhões de hectares, distribuídas nas regiões tropicais e subtropicais da África, Ásia e América (Singh et al., 2002).

A caracterização morfológica fornece uma série de informações a respeito da variabilidade genética de cada material estudado. Esses dados auxiliam na caracterização de germoplasma, possibilitando avanços na descrição da diver- gência genética entre linhagens (Singh, 2001).

Os trabalhos de melhoramento de caupi no Brasil ainda são escassos e as cultivares disponíveis estão sendo utilizadas sem se considerar as suas possíveis diferenças de comportamento nas diversas regiões de cultivo. Portanto, a caracterização morfológica de linhagens de caupi é importante porque possibilita o registro e identificação, facilitando o acesso a esse material em busca de plantas com boa resposta em termos de produtividade e comportamento em diferentes condições ambientais.

O objetivo deste trabalho foi avaliar a produtividade e caracterizar a morfologia de dez acessos de caupi nas condições edafoclimáticas do município de Mossoró, RN.

\section{MATERIAL E MÉTODOS}

$\mathrm{O}$ experimento foi realizado em campo da UFERSA, em Mossoró, cujas coordenadas geográficas são $5^{\circ} 11^{\prime}$ de latitude sul e $37^{\circ} 20^{\prime}$ de longitude oeste. O clima da região, segundo a classifi- cação de Koppen, é seco e muito quente, com duas estações climáticas: uma seca que vai geralmente de junho a janeiro e outra chuvosa, de fevereiro a maio, apresentando temperatura média anual de $27^{\circ} \mathrm{C}$, precipitação pluviométrica anual irregular com média de $673 \mathrm{~mm}$, umidade relativa do ar de $68 \%$ e luminosidade de 241,7 h mês ${ }^{-1}$ (Amaro Filho, 1991). A análise de solo indicou: $\mathrm{pH}$ em água $=6,8$; $\mathrm{P}$ disponível $=149,00 \mathrm{mg} \mathrm{dm}^{-3} ; \mathrm{K}=93,00 \mathrm{mg}$ $\mathrm{dm}^{-3} ; \mathrm{Al}$ trocável $=0,0 \mathrm{cmol} \mathrm{dm}{ }^{-3} ; \mathrm{Ca}^{+2}$ $+\mathrm{Mg}=3,75 \mathrm{cmol} \mathrm{dm}^{-3}$ e matéria orgânica $=14,2 \mathrm{~g} \mathrm{dm}^{-3}$.

O delineamento experimental utilizado foi blocos casualizados com dez tratamentos e quatro repetições. As parcelas experimentais foram constituídas por 30 plantas (três fileiras de dez plantas), sendo as avaliações realizadas na fileira central. Os tratamentos compuseram-se dos acessos de caupi: Amapá, BRS Potiguar, Canapu, Casca-de-seda, Coruja, Costela-de-vaca, João-vieira, Pingo-de-ouro, Rabo-de-peba e Sempreverde, que foram obtidas junto a pequenos produtores e feiras livres de diver- 
Tabela 1. Análise de variância e médias dos caracteres número de dias para emergência (NDE), hábito de crescimento (HC), período médio para início do florescimento (PMIF), porte da planta (PP), comprimento da vagem (CV), número de vagens por planta (NVP), número de sementes por vagem (NSV), peso 100 sementes (PCS) e produtividade (P) de dez acessos de feijão-vigna [Vigna unguiculata (L.) Walp.](variance analysis and average values of the characteristics number of days to emergence (NDE), growth habit (HC), average period to emit flowers (PMIF), plant stature (PP), pod length (CV), number of pods per plant (NVP), number of seeds per pod (NSV), weight of 100 seeds (PCS) and yield (P) of 10 cowpea accessions). Mossoró, UFERSA, 2007.

\begin{tabular}{|c|c|c|c|c|c|c|c|c|c|}
\hline Acessos & $\begin{array}{l}\text { NDE } \\
\text { (dias) }\end{array}$ & $\mathrm{HC}$ & PMIF & PP & $\mathrm{CV}(\mathrm{cm})$ & NVP & NSV & $\operatorname{PCS}(g)$ & $P\left(t h a^{-1}\right)$ \\
\hline $\mathrm{QM}$ & $0,46^{* *}$ & - & $247,56^{*}$ & - & $21,62^{*}$ & $14,64^{*}$ & $3,64^{* *}$ & $17,65^{\star}$ & $46,79^{*}$ \\
\hline C.V (\%) & 6,42 & - & 2,54 & - & 2,36 & 3,59 & 2,41 & 1,59 & 7,68 \\
\hline Amapá & $5 a b$ & Indeterminado & 55 a & Semi-enramador volúvel & $20,6 \mathrm{e}$ & $11 \mathrm{a}$ & $13 \mathrm{~b}$ & $18,66 \mathrm{f}$ & $1,60 \mathrm{a}$ \\
\hline BRS Potiguar & $5 a b$ & Indeterminado & 56 a & Semi-enramador & $23,0 \mathrm{~b}$ & $9 \mathrm{~b}$ & $13 \mathrm{~b}$ & $21,51 d$ & $1,51 \mathrm{~b}$ \\
\hline Canapu & $6 \mathrm{~b}$ & Indeterminado & $79 \mathrm{f}$ & Semi-enramador volúvel & $17,0 \mathrm{f}$ & $3 \mathrm{~g}$ & $12 b$ & $21,31 \mathrm{e}$ & $0,46 \mathrm{i}$ \\
\hline Casca-de-seda & 4 a & Indeterminado & $60 \mathrm{~b}$ & Semi-enramador volúvel & $22,0 \mathrm{c}$ & $8 \mathrm{c}$ & $13 b$ & $23,30 \mathrm{c}$ & $1,39 \mathrm{c}$ \\
\hline Coruja & $5 a b$ & Indeterminado & $65 c$ & Semi-enramador volúvel & 20,4 e & $7 d$ & $16 a$ & $17,78 \mathrm{~g}$ & $1,19 \mathrm{e}$ \\
\hline Costela-de-vaca & $5 a b$ & Indeterminado & $64 c$ & Semi-enramador volúvel & $25,0 \mathrm{a}$ & $7 d$ & $12 b$ & 23,47 a & $1,18 \mathrm{f}$ \\
\hline João-vieira & $5 a b$ & Indeterminado & $66 \mathrm{~cd}$ & Semi-enramador volúvel & $20,7 \mathrm{e}$ & $4 \mathrm{f}$ & $13 b$ & $17,55 \mathrm{~h}$ & $0,55 \mathrm{~g}$ \\
\hline Pingo-de-ouro & $5 a b$ & Indeterminado & $91 \mathrm{~g}$ & Semi-enramador volúvel & $14,0 \mathrm{~g}$ & $3 \mathrm{~g}$ & $12 b$ & 15,86 j & $0,34 \mathrm{j}$ \\
\hline Rabo-de-peba & $5 a b$ & Indeterminado & $73 \mathrm{e}$ & Semi-enramador volúvel & $17,0 \mathrm{f}$ & $4 \mathrm{f}$ & $13 \mathrm{~b}$ & $15,90 \mathrm{i}$ & $0,49 \mathrm{~h}$ \\
\hline Sempre-verde & $5 a b$ & Indeterminado & $71 \mathrm{~d}$ & Semi-enramador volúvel & $21,0 d$ & $6 \mathrm{e}$ & $15 a$ & $23,45 b$ & $1,27 \mathrm{~d}$ \\
\hline
\end{tabular}

Médias seguidas da mesma letra, na coluna, não diferem entre si pelo teste Tukey, a 5\% de probabilidade; *,**ignificativo aos níveis de $5 \%$ e $1 \%$ de probabilidade pelo teste F, respectivamente (means followed by the same letters in the column did not differ from each other, Tukey test, $5 \%$; ***significant at $5 \%$ and $1 \%$ probability through $\mathrm{F}$ test, respectively).

sos municípios do estado do Rio Grande do Norte.

Antes da semeadura, realizou-se o preparo do solo, seguido de gradagem e coveamento com enxadão. No momento da semeadura, aplicou-se por cova um litro de esterco bovino curtido e seco. $\mathrm{O}$ espaçamento adotado foi de 1,00 x 0,50 $\mathrm{m}$, sendo semeadas em cada cova três sementes. Após a germinação, foi realizado o desbaste, deixando-se uma planta por cova. $\mathrm{O}$ controle de plantas invasoras foi realizado por meio de duas capinas manuais no período anterior ao florescimento. Durante a condução da cultura foram realizadas pulverizações à base de deltametrina 2,5E, para combater a cigarrinha do feijoeiro (Empoasca krameari). Foram realizadas irrigações por gotejamento, de forma a suplementar as necessidades da cultura, próximo ao final do período chuvoso.

Durante o experimento foram anotados o período para emergência das plântulas, hábito de crescimento, período médio para início do florescimento, porte da planta, comprimento médio da vagem, número médio de vagens por planta, número médio de sementes por vagem, peso de 100 sementes e produtividade. Os dados de produção e de medições de vagens foram submetidos à análise de variância e a comparação de médias foi feita pelo teste Tukey, a $5 \%$ de probabilidade.

\section{RESULTADOS E DISCUSSÃO}

Verificaram-se diferenças estatísticas significativas entre os genótipos para todas as características analisadas (Tabela 1). O período de emergência variou de quatro a seis dias, sendo os genótipos Casca-de-seda e Canapu o mais precoce e tardio, respectivamente, embora não tenham diferido significativamente dos demais genótipos. Todos os acessos expressaram hábito de crescimento indeterminado e porte da planta semi-enramador volúvel, exceto BRS Potiguar, que se revelou semienramador.

Houve diferenças de até 36 dias entre acessos para que, pelo menos $50 \%$ das plantas estivessem em floração. Os acessos Amapá e BRS Potiguar detiveram 50\% das plantas em floração aos 55 e 56 dias, respectivamente, após a semeadura, enquanto o acesso Pingo-deouro foi o mais tardio, atingindo este índice aos 91 dias.

O comprimento médio da vagem variou de 14 a $25 \mathrm{~cm}$, para Pingo-deouro e Costela-de-vaca, respectivamente. Nesse sentido, observa-se que os acessos Canapu, Rabo-de-peba e Pingo- de-ouro obtiveram tamanhos de vagens abaixo dos padrões comerciais, que, segundo Pereira et al. (1992), Silva \& Oliveira (1993) e Miranda et al. (1996) é acima de $20 \mathrm{~cm}$ de comprimento. Comprimentos de vagens superiores a $20 \mathrm{~cm}$ foram verificados nos acessos Amapá, BRS Potiguar, Casca-de-seda, Coruja, Costela-de-vaca, João-vieira e Sempre-verde.

Com relação ao número de vagens por planta, destacou-se o acesso Amapá, com 11 vagens. Por outro lado, Canapu e Pingo-de-ouro contiveram os menores números de vagens por planta, seguidos por João-vieira e Rabo-de-peba.

Coruja e Sempre-verde expressaram o maior número de sementes por vagem, 16 e 15, respectivamente; enquanto para os demais a variação foi de 12 a 13 , não havendo diferença estatística significativa. Observa-se ainda que o peso médio de 100 sementes variou de 15,86 g (Pingo-de-ouro) a 23,47 g (Costela-devaca).

O acesso mais produtivo foi Amapá,

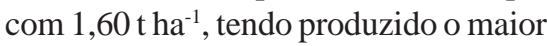
número e vagens por planta; seguido por BRS Potiguar (1,51 t ha-1) e Casca-deseda $\left(1,39 \mathrm{tha}^{-1}\right)$. Por sua vez, os acessos menos produtivos, em ordem decrescente, foram Rabo-de-peba $\left(0,49 \mathrm{t} \mathrm{ha}^{-1}\right)$, Canapu $\left(0,46 \mathrm{t} \mathrm{ha}^{-1}\right)$ e Pingo-de-ouro 
(0,34 t ha $\left.{ }^{-1}\right)$, que produziram, também, o menor número de vagens por planta.

Considerando que o caupi é uma significativa fonte de proteína e de renda para a população menos favorecida da região Nordeste, os resultados desta pesquisa fornecem subsídios para programas de melhoramento, visando a seleção de materiais adaptados às condições edafoclimáticas da região.

Face aos resultados obtidos, para a região de Mossoró, pode ser indicado como alternativa de cultivo experimental ao produtor, o acesso Amapá, por ser mais precoce, possuir maior número de vagens por planta e maior produtividade. BRS Potiguar e Casca-de-seda poderão também atender a esse propósito por apresentarem produtividade e comprimento de vagens superiores além de serem precoces.

\section{REFERÊNCIAS}

AMARO FILHO J. 1991. Contribuición al estúdio del clima del Rio Grande do Norte. Madrid: ETSIA/UPM. 311p. (Tese doutorado).

MAIA AF; ASSUNÇÃO MV; ALVES JF. 1986. Influência do método de debulha e da unidade na produção de sementes de feijão de corda. Ciência Agronômica 17: 91-100.

MIRANDA P; COSTA AF; OLIVEIRA LR; TAVARES JA; PIMENTEL ML; LINS GML. 1996. Comportamento de cultivares de Vigna unguiculata (L.) Walp., nos sistemas solteiro e consorciado. VI - Tipos ereto e semi-ereto. Pesquisa Agropecuária Pernambucana 9: 95105.
PEREIRA JA; BELARMINO FILHO J; SANTOS JF; ARANJA VS. 1992. Caracteres agronômicos e suas correlações em linhagens de feijão-macassar. João Pessoa: EMEPA, 25p. (Boletim de Pesquisa, 6).

SILVA PSL; OLIVEIRA CN. 1993. Rendimentos de feijão verde e maduro de cultivares de caupi. Horticultura Brasileira 11: 133-135.

SINGH BB; EHLERS JD; SHARMA B; FREIRE FILHO FR. 2002. Recent progress in cowpea breeding. In: FATOKUN CA; TARAWALI SA; SING BB; KORMAWA PM; TAMO M. (eds.). Challengens and opportunities for enchancing sustainable cowpea production. Ibadan: IITA. p.22-40.

SINGH SP. 2001. Broadening the genetic base of common bean cultivars: a review. Crop Science 41: 1659-1675 